\title{
PRE-SERVICE ENGINEER EDUCATORS LEARNING MATHEMATICS: MAPPING THE LIVED COMPLEXITY
}

\author{
Katerina Kasimatis ${ }^{1}$, Andreas Moutsios-Rentzos ${ }^{2}$, Nikolaos Matzakos ${ }^{1}, \operatorname{Varvara}_{\text {Rozou }}{ }^{3}$, \\ \& Dionisios Kouloumpis ${ }^{4}$ \\ ${ }^{I}$ Department of Education, School of Pedagogical and Technological Education ASPETE (Greece) \\ ${ }^{2}$ Department of Primary Education, National and Kapodistrian University of Athens (Greece) \\ ${ }^{3}$ Department of Philosophy, National and Kapodistrian University of Athens (Greece) \\ ${ }^{4}$ Department of Educational Studies, National and Kapodistrian University of Athens (Greece)
}

\begin{abstract}
In this paper, we adopt a systemic perspective to investigate the teaching of mathematics in ASPETE, which is a tertiary education institute in Greece that offers a two-faceted degree: an engineer degree and a pedagogical degree as engineer educators. We focus on the complex lived reality of first year Electrical Engineers students through a multileveled affective mapping of their studying in ASPETE, including: approaches to study, confidence in learning mathematics, conceptions about mathematics and its role in their studies and career, and views about mathematics teaching effectiveness (considering both what they actually experienced and what they would prefer to experience). The results of our study suggest that the students show a lack of preference for the surface approach (though not combined with a preference for a deep approach), neutral-positive confidence in learning mathematics, whilst they seemed to be satisfied by the teachers' effectiveness. Qualitative differences in the affective relationship with mathematics were identified with respect to the students' approach to study. Finally, the students' conceptions about mathematics seemed to be related with the desired characteristics of mathematics teaching.
\end{abstract}

Keywords: System, approaches to study, mathematics teaching effectiveness, mathematics conceptions, mathematics confidence.

\section{Introduction}

The modern sociocultural interactions appear to entail a continuously increasing level of quantitative and logical reasoning skills. Moreover, mathematics is at the crux of the contemporary curricula and the broader educational systems, whilst mathematics is also the language of communicating and producing scientific results. In this study, we focus on the role of mathematics in ASPETE, a Greek tertiary education institute, which offers its graduates both an engineer degree and a pedagogical degree as engineer educator (who may teach in vocational high schools in Greece). This inherently two-faceted degree constitutes a complex educational environment. In a broader research project (Mathematics education and Technological Education; MATHETE) we adopted a systemic perspective (Moutsios-Rentzos \& Kalavasis, 2016) and built upon previous studies (Moutsios-Rentzos, \& Kasimati, 2014) to investigate mathematics teaching and learning in ASPETE. In this paper, we report aspects of that broader project focusing on the lived complexity of first year Electrical Engineers students of ASPETE.

\section{Mapping the lived complexity of learning mathematics in ASPETE: A multileveled affective mapping}

A system is defined as a complex whole, the parts of which are interrelated towards specific goals, thus significantly differing from a mere "heap" of parts (Bertalanffy, 1968). Hence, ASPETE may be conceptualised as an open learning system, being at the same time a subsystem of the broader educational system and the social system (cf. Kalavasis, \& Kazadi, 2015). In this study, we drew upon Moutsios-Rentzos and Kalavasis (2016) to include in our investigations about mathematics the broader experience with studying in ASPETE. Hence, we map the students' relationship with studying in ASPETE, their affective relationship with learning mathematics in ASPETE, as well as their interlinkings. Our approach is diagrammatically summarised in Figure 1. 
Figure 1. Learning mathematics in the educational unit: a mapping of the lived complexity (drawing upon Moutsios-Rentzos \& Kalavasis, in preparation).

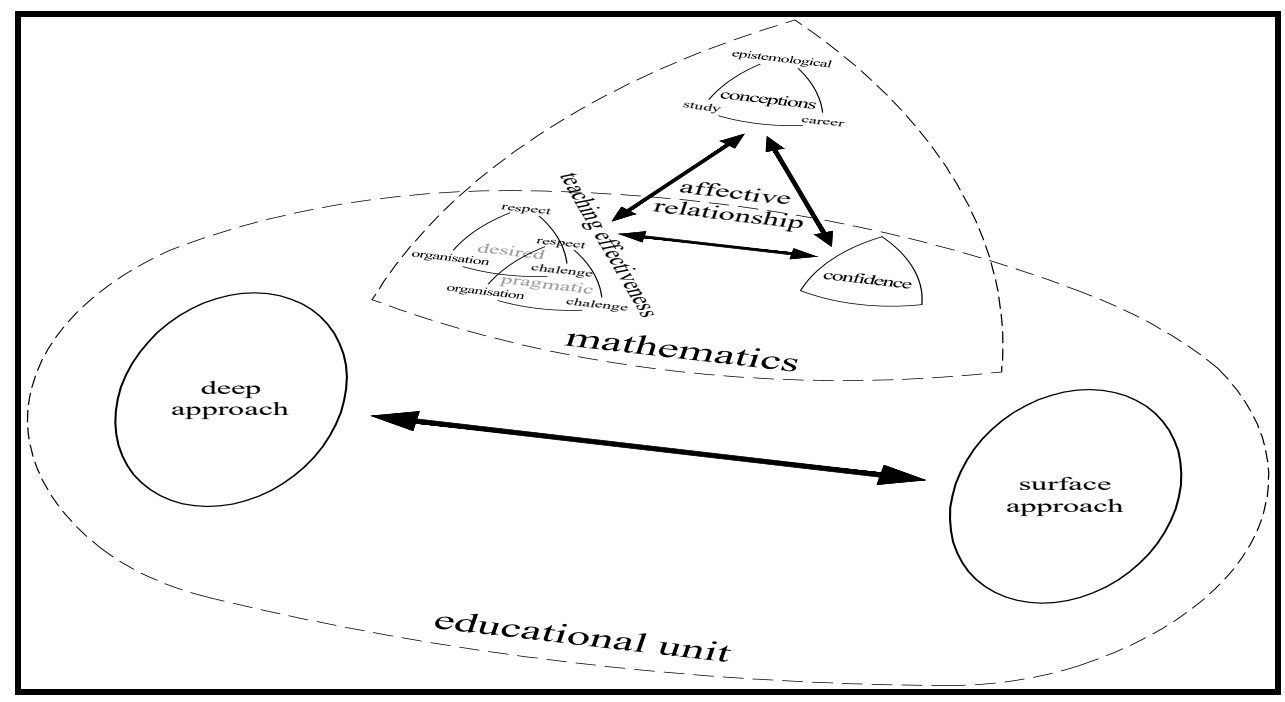

The students' broader studying experience in ASPETE is investigated through their approaches to study (Marton \& Säljö, 1976), referring to the specific manner in which students respond to a study situation. Two main approaches have been identified: a deep approach refers to focusing on the meaning and the ideas contained in a task, whilst a surface approach refers to focussing on the superficial characteristics and requirements of a task. In an educational unit, approaches to study may be conceptualised as the result of the constant negotiation between the students' learning characteristics and the requirements of the specific learning environment, as reflected on the students' academic outcomes.

The students' broader studying experience in ASPETE is intertwined with their narrower experience with learning mathematics in ASPETE (see Figure 1). The students' affective relationship with learning mathematics, conceptualised as a dynamic affect system (Pepin \& Roesken-Winter, 2014), constitutes of three interacting components: a) conceptions about mathematics, b) confidence about coping with mathematics, and c) views about mathematics teaching effectiveness. Considering conceptions about mathematics, we drew upon our systemic perspective to consider mathematics within diverse systems: within the system of scientific disciplines, within the educational system, and within the occupational system. The work of Wood, Petocz and Reid (2012) fits with this, as they investigated the conceptions of undergraduate students about their epistemological conceptions of mathematics, their conceptions about the role of mathematics in their future studies and in their future career. Their findings suggest that the epistemological conceptions about mathematics may be classified as: a) 'numbers/components' (individual and isolated components, techniques and calculations), b) 'abstract/models' (models of the real-world phenomena), and c) 'life' (a way of thinking and interpreting the world). The conceptions about the role of mathematics in their future studies and career, appeared to be: a) practical (focused on calculations, problem solving, and logical thinking), b) generic (referring to a generic mathematical way of thinking and of its importance in studies and career), and c) (lack of) knowledge (referring to the lack of knowing of the exact role of mathematics in studies and career).

Furthermore, we included in our mapping the students' confidence about learning mathematics, as well as their views about effective mathematics teaching. Fennema and Sherman (1976) developed the widely cited Fennema-Sherman Mathematics Attitude Scales, which included a scale that identifies the degree of confidence that an individual experiences with respect to his/her "ability to learn and to perform well on mathematical tasks" (p. 326). Considering mathematics teaching effectiveness, we chose to consider the broader educational literature to obtain a broader perspective to teaching effectiveness (Patrick \& Smart, 1998). Furthermore, in our investigations we drew upon Moutsios-Rentzos and Kalavasis (2016) to differentiate the pragmatic representation of mathematics teaching effectiveness (referring to the perceived phenomenon as actually occurring in the educational unit) from the desired/intentioned representation (referring to the desired state of the phenomenon). Following these, for the purposes of this study, we adapted the research of Patrick and Smart (1998) about teaching effectiveness. They conceptualised teaching effectiveness to consists of three dimensions, namely: respect for students, ability to challenge students, organisation and presentation skills. In this project, the tri-faceted conceptualisation of teaching effectiveness was conceptualised to include both a pragmatic representation and a desired/intentioned representation (see Figure 1). 
Consequently, in this study, we attempt to obtain a mapping of the lived complexity of learning mathematics in ASPETE, through a multileveled affective mapping. First, we investigate the narrower affective relationship with mathematics; a dynamic affect system including: the students' conceptions (epistemological, studies, career), their confidence about coping with mathematics, their views about mathematics teaching effectiveness (pragmatic, desired/intentioned) and their links. Moreover, we explore the broader relationship with studying in ASPETE through the students' approaches to study. Finally, we focus on the links between the broader and the narrower relationship.

\section{Methods and procedures}

The study was conducted with first-year Electrical Engineer students of ASPETE (N=56; 14 females), in the end of the first semester of the academic year 2018-2019. A five-section questionnaire was employed, including a section about demographic details and four sections about approaches to study, mathematics conceptions, confidence about mathematics and mathematics teaching effectiveness: A) Approaches to study were identified by Revised Two-Factor Study Process Questionnaire (R-SPQ-2F; Biggs, Kember, \& Leung, 2001), as employed by Kasimati, Moutsios-Rentzos and Matzakos (2016) with ASPETE students, showing good cross-cultural validity and reliability. R-SPQ-2F consists of 20 (10 for each approach) 5-point Likert-type items. B) The students' conceptions about mathematics were identified through the questionnaire of Wood et al. (2012) as employed by Moutsios-Rentzos and Kassimati (2014) with ASPETE students, showing its good cross-cultural psychometrics. The questionnaire consists of 46 five-point Likert type items organised in three parts, in accordance with the three dimensions it identifies: epistemological (16 items), studies (14 items), career (16 items). C) The students' confidence about mathematics was identified through the Confidence in Learning Mathematics Scale (Fennema \& Sherman, 1976), consisting of 12, 5-point Likert type items. D) The students' views about mathematics teaching were modified through a modified version of Patrick and Smart's (1998) instrument. Each of the 24, 5-point Likert type items of the original questionnaire was transformed to a dyad: the first part asking the students to reflect upon the actual teaching and the second part upon their desired teaching reality.

The descriptive and non-parametric inferential analyses were conducted with SPSS 25, including One-sample Wilcoxon signed rank tests and Kendall's tau correlations.

\section{Results}

The results of our analyses are summarised in Table 1. Considering the students' broader experience with studying in ASPETE, though they appear not to statistically significantly prefer a deep approach, they seem to statistically significantly move away from a surface approach.

Regarding their affective relationship with mathematics, all the measured aspects statistically significantly differed from the conceptual neutral (see Table 1). Nevertheless, the differences identified in confidence, the desired/intentioned reality of teaching effectiveness, an epistemological conception (life) and two career conceptions (generic and knowledge) were not large enough to be assigned to a different characterization from the conceptual neutral. Considering the remaining differences, the students' pragmatic representations about teaching effectiveness were on the positive, suggesting their being satisfied by the experienced mathematics teaching in ASPETE. The students appeared to conceptualise mathematics as being abstract models and about techniques and calculations. With respect to the role of mathematics in their future studies, the students appear to identify the practical and the generic aspect of mathematics, whilst they also identify the practical aspect of mathematics in their future career. Regarding the pragmatic representation of teaching effectiveness, the students expressed their statistically significantly positive experiences in respect, organization and challenge.

Subsequently, we investigated the links within the dynamic affect system about mathematics. Confidence was not statistically significantly correlated with any other aspects of the affective relationship. Considering the links between teaching effectiveness and conceptions, statistically significant correlations were found only with the desired/intentioned reality. In specific, lack of knowledge about the role of mathematics in their future career had a statistically significant negative correlation with their desire for more respect $(\tau=-0.282, P=0.039)$. Furthermore, their preference for challenge in teaching had statistically significant positive correlations with their epistemological conception that mathematics is about techniques and calculations $(\tau=0.345, P=0.011)$ and is related to life ( $\tau=0.281, P=0.042)$. 
Table 1. Learning mathematics and studying in ASPETE: a mapping of the lived complexity.

\begin{tabular}{|c|c|c|c|c|c|c|}
\hline \multicolumn{2}{|c|}{ 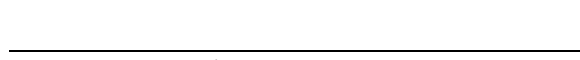 } & $M$ & $M d n$ & $P$ & Deep approach & Surface approach \\
\hline \multicolumn{2}{|c|}{ Deep approach } & $3.0^{1}$ & 3.0 & $0.837^{4}$ & & \\
\hline \multicolumn{2}{|c|}{ Surface approach } & $2.5^{1}$ & 2.5 & $0.002^{4}$ & & \\
\hline \multirow{2}{*}{\multicolumn{2}{|c|}{ Confidence in learning mathematics }} & $3.3^{2}$ & 3.0 & $<0.001^{5}$ & $\tau^{7} 0.281$ & -0.334 \\
\hline & & & & & $P \quad 0.027$ & 0.008 \\
\hline \multirow[t]{4}{*}{ Respect } & \multirow[t]{2}{*}{ Pragmatic } & $4.1^{2}$ & 4.3 & $<0.001^{5}$ & $\tau \quad 0.119$ & -0.003 \\
\hline & & & & & $P \quad 0.256$ & 0.979 \\
\hline & \multirow[t]{2}{*}{ Desired/Intentioned } & $3.3^{3}$ & 3.0 & $<0.001^{6}$ & $\tau \quad 0.146$ & -0.231 \\
\hline & & & & & $P \quad 0.181$ & 0.034 \\
\hline \multirow[t]{4}{*}{ Organisation } & \multirow[t]{2}{*}{ Pragmatic } & $4.2^{2}$ & 4.4 & $<0.001^{5}$ & $\tau \quad 0.170$ & -0.057 \\
\hline & & & & & $P \quad 0.109$ & 0.589 \\
\hline & \multirow[t]{2}{*}{ Desired/Intentioned } & $3.3^{3}$ & 3.0 & $<0.001^{6}$ & $\tau \quad-0.034$ & -0.129 \\
\hline & & & & & $P \quad 0.762$ & 0.249 \\
\hline \multirow{4}{*}{ Challenge } & \multirow[t]{2}{*}{ Pragmatic } & $3.9^{2}$ & 3.9 & $<0.001^{5}$ & $\tau \quad 0.147$ & -0.069 \\
\hline & & & & & $P \quad 0.162$ & 0.513 \\
\hline & \multirow[t]{2}{*}{ Desired/Intentioned } & $3.3^{3}$ & 3.0 & $<0.001^{6}$ & $\tau \quad 0.168$ & -0.107 \\
\hline & & & & & $\begin{array}{ll}P & 0.127\end{array}$ & 0.329 \\
\hline \multirow[t]{6}{*}{ Conceptions } & \multirow[t]{2}{*}{ Number/Components } & $3.8^{2}$ & 3.8 & $<0.001^{5}$ & $\tau \quad 0.131$ & -0.008 \\
\hline & & & & & $\begin{array}{ll}P & 0.309\end{array}$ & 0.950 \\
\hline & \multirow[t]{2}{*}{ Modelling/Abstract } & $3.9^{2}$ & 4.3 & $<0.001^{5}$ & $\tau \quad 0.165$ & 0.191 \\
\hline & & & & & $P \quad 0.210$ & 0.145 \\
\hline & \multirow[t]{2}{*}{ Life } & $3.3^{2}$ & 3.3 & $0.008^{5}$ & $\tau \quad 0.033$ & -0.155 \\
\hline & & & & & $P \quad 0.800$ & 0.230 \\
\hline \multirow[t]{6}{*}{ Studies } & \multirow[t]{2}{*}{ Practical } & $3.9^{2}$ & 4.0 & $<0.001^{l}$ & $\tau \quad 0.035$ & 0.099 \\
\hline & & & & & $\begin{array}{ll}P & 0.789\end{array}$ & 0.442 \\
\hline & \multirow[t]{2}{*}{ Generic } & $3.6^{2}$ & 3.5 & $<0.001^{l}$ & $\tau \quad 0.004$ & 0.096 \\
\hline & & & & & $P \quad 0.975$ & 0.460 \\
\hline & \multirow[t]{2}{*}{ (lack of) Knowledge } & $4.0^{2}$ & 4.0 & $<0.001^{l}$ & $\tau \quad 0.152$ & 0.181 \\
\hline & & & & & $P \quad 0.251$ & 0.171 \\
\hline \multirow[t]{6}{*}{ Career } & \multirow[t]{2}{*}{ Practical } & $3.8^{2}$ & 4.0 & $<0.001^{l}$ & $\tau \quad 0.013$ & 0.130 \\
\hline & & & & & $P \quad 0.923$ & 0.321 \\
\hline & \multirow[t]{2}{*}{ Generic } & $3.3^{2}$ & 3.3 & $0.002^{l}$ & $\tau \quad 0.034$ & 0.104 \\
\hline & & & & & $P \quad 0.790$ & 0.416 \\
\hline & \multirow[t]{2}{*}{ (lack of) Knowledge } & $3.6^{2}$ & 3.4 & $<0.001^{l}$ & $\tau \quad 0.075$ & 0.183 \\
\hline & & & & & $P \quad 0.561$ & 0.154 \\
\hline
\end{tabular}

1'1': never or rarely true of me, '2': sometimes true of me, '3': this item is true of me about half the time, '4': frequently true of me. ' 5 ': almost always true of me. ' ' 1 ': strongly disagree, '2': disagree, ' 3 ': neither agree, nor disagree, '4': agree. '5': strongly agree. ${ }^{3}$ ' 1 ': considerably less frequently, '2': less frequently, ' 3 ': as frequently as it did, '4': more frequently. ' 5 ': much more frequently. ${ }^{4}$ One-sample Wilcoxon signed rank test to the hypothesised median "3": "this item is true of me about half the time". ${ }^{5}$ One-sample Wilcoxon signed rank test to the hypothesised median "3": "neither agree, nor disagree". ${ }^{6}$ One-sample Wilcoxon signed rank test to the hypothesised median " 3 ": "as frequently as it did". ${ }^{7}$ Kendall's tau $\tau$ non-parametric correlation.

Finally, we investigated the links between the broader experience with studying in ASPETE and their narrower experience of learning mathematics in ASPETE (see Table 1). Confidence was statistically significantly positively correlated with the deep approach and negatively correlated with the surface approach. Thus, it appears that the students who in general prefer to learn about ideas and meaning are also more confident with learning mathematics. Moreover, surface approach was statistically significantly negatively correlated with a preference for challenge in teaching. This may be related to the fact that respect for teaching is not clearly related to the subject matter of the teaching itself and, therefore, is conceptually incompatible with the surface approach.

\section{Discussion and concluding remarks}

In this paper, we discussed a multileveled affective mapping of the complex lived reality that the first year Electrical Engineers of ASPETE experience with respect to mathematics. We adopted a systemic approach to include in our investigations the broader experience about studying in ASPETE. We proposed a dynamic affect system, including confidence in learning mathematics, their conceptions about mathematics and its role in their studies and career, and their views about mathematics teaching effectiveness (considering both what they actually experienced and what they would prefer to 
experience). The results of the conducted analyses in general accorded with and enriched previous studies (Moutsios-Rentzos, \& Kasimati, 2014; Kasimati, Moutsios-Rentzos, \& Matzakos, 2016; Wood, Petocz, \& Reid, 2012) revealing, for example, that the students show a lack of preference for the surface approach (though not combined with a preference for a deep approach) and that they consider mathematics as being mainly about models and techniques. Moreover, they expressed a neutral-positive confidence in learning mathematics, and they appeared to be satisfied with the actual mathematics teaching, identifying area for improvement. Furthermore, our approach allowed for investigations both within the affective system and, importantly, between the affective system and the broader experience. Considering the mathematics affective relationships, the students' conceptions about mathematics seemed to be related with the desired characteristics of mathematics teaching. For example, those who consider mathematics more relevant with their everyday lives, would like more mental challenges in the teaching of mathematics. Moreover, it seems that the lower the conception of the exact role of mathematics in their future careers, the greater the desire to have more respect in teaching. Finally, confidence and surface approach appeared to be the main links between the broader and the narrower level of experience. Following these, it is argued that the proposed approach accords with the existing findings, allowing at the same time to meaningfully extend these investigations to include further relationships and inter-relationships. Consequently, current investigations within the broader research project (MATHETE) focus on systemic investigation about teaching and learning mathematics in ASPETE.

\section{Acknowledgements}

This work has been (co-)financed by the Greek School of Pedagogical and Technological Education through the operational program "Research strengthening in ASPETE"- Project 80147: "Mathematics Education and Educational Technology; MATHETE".

\section{References}

Bertalanffy, L. V. (1968). General System Theory: Foundations, Development, Applications. NY: George Braziller.

Biggs, J. B., Kember, D., \& Leung, D. Y. P. (2001) The Revised Two Factor Study Process Questionnaire: R-SPQ-2F. British Journal of Educational Psychology, 71, 133-149.

Fennema, E., \& Sherman, J. A. (1976). Fennema-Sherman mathematics attitudes scales: Instruments designed to measure attitudes toward the learning of mathematics by females and males. Journal for research in Mathematics Education, 7(5), 324-326.

Kalavasis, F., \& Kazadi, C. (2015). The learning and teaching of mathematics as an emergent property through interacting systems and interchanging roles: a commentary. In U. Gellert, J. Gimenez Rodriguez, C. Hahn \& S. Kafoussi (Eds.), Educational Paths to Mathematics. A C.I.E.A.E.M. Sourcebook (pp. 425-429). Dordrecht: Springer.

Kasimati, K., Moutsios-Rentzos, A., \& Matzakos, N. (2016). Antilipsis yia to rolo ton mathimatikon stis spoudes kai stin ergasia kai prosengisis meletis: i periptosi tis A.S.PAI.TE. [Conceptions about the role of mathematics in studies and career and approaches to study: the case of ASPETE]. Proceedings of the $33^{\text {rd }}$ Panhellenic conference of Mathematics education of the Hellenic Mathematical Society (pp. 418-426). Chania, Greece: HMS.

Marton, F., \& S lj , R. (1976). On qualitative differences in learning - I: outcome and process. British Journal of Educational Psychology, 46, 4-11.

Moutsios-Rentzos, A., \& Kasimati, K. (2014). Mathimatika, spoudes, kariera: dierevnontas tis antilipsis phititon tis ASPAITE [Mathematics, studies, career: an investigation about the conceptions of ASPETE students]. Proceedings of the Conference of the Greek Association for Research in Mathematics Education (5th GARME). 14-16 March 2014, Florina, Greece: GARME.

Moutsios-Rentzos, A., \& Kalavasis, F. (2016). Systemic approaches to the complexity in mathematics education research. International Journal for Mathematics in Education, 7, 97-119.

Patrick, J., \& Smart, R. M. (1998). An empirical evaluation of teacher effectiveness: The emergence of three critical factors. Assessment \& Evaluation in Higher Education, 23(2), 165-178.

Pepin, B., \& Roesken-Winter, B. (Eds.). (2014). From beliefs to dynamic affect systems in mathematics education: Exploring a mosaic of relationships and interactions. Springer.

Wood, L. N., Petocz, P., \& Reid, A. (2012). Becoming a mathematician. Dordrecht: Springer. 